\title{
Association of Self-Presentational Strategies on Facebook and Positive Feedback in Adolescence - A Two-Study Approach
}

\author{
Anna Metzler* and Herbert Scheithauer \\ Freie Universität Berlin, Germany
}

\begin{abstract}
As Facebook enables adolescents to present themselves positively by means of their Facebook profile and to gain positive feedback for doing so, the aim of the current study is to investigate which kinds of adolescents' positive self-presentation in profile pictures and status updates are associated with positive feedback in terms of Likes from the Facebook community, considering gender differences. Data for this study were based on adolescents aged $14-17$ years, pursuing a two-method approach, using questionnaire data $(N=703 ; 71.7 \%$ female; $\mathrm{M}_{\mathrm{age}}=15.76$ years $)$ as well as data from content analysis $\left(N=143 ; 63 \%\right.$ female; $\mathrm{M}_{\mathrm{age}}=15.72$ years $)$. Hierarchical multiple regressions were used. The results suggest that the self-presentational strategy of ingratiation seems to be the most advantageous in eliciting positive feedback. In particular, presenting oneself in the company of friends as well as posting about spending time with friends were related to positive feedback.
\end{abstract}

\section{Keywords}

Computer-mediated communication, self-presentation, Facebook, adolescence, content analysis

Adolescents' motives for using social networking sites (SNSs) such as Facebook are quite similar to those for engaging in face-to-face interactions: to maintain social relationships, to present oneself to others (Ellison, Steinfield, \& Lampe, 2007; Nadkarni \& Hofmann, 2012; Spies Shapiro \& Margolin, 2014), and to receive feedback for one's self-presentational behavior (Smith, 2014). Given that adolescents are typically concerned with peer acceptance as well as the impression they convey (Harter, 1998; Hartup, 1996), they are very likely to create SNS profiles (Livingstone, 2008). Self-presentation enables adolescents to demonstrate who they are by means of their Facebook profile and to gain positive feedback for doing so (Valkenburg, Peter, \& Schouten, 2006), in the context of Facebook, for instance, in terms of

\footnotetext{
*Address for correspondence

Anna Metzler, Department of Education and Psychology, Freie Universität Berlin, Berlin, Germany. E-mail: annarehm@zedat.fuberlin.de.
}

Likes. A Like on Facebook is a one-click action that expresses individuals' favorable attitudes towards content produced by other users (Hong, Chen, \& Li, 2017). As peers gradually take on a central role in the relational network (Furman \& Buhrmester, 1993; Helsen, Vollebergh, \& Meeus, 2000), adolescents can benefit from the positive interactions on SNSs in terms of developmental demands (Spies Shapiro \& Margolin, 2014). This may hold especially true in the context of Facebook, as positive reactions are even more beneficial when received from one's peers (Zimmer-Gembeck \& Skinner, 2011) - which is usually the case on Facebook.

Building on both the theoretical framework of self-presentational strategies developed by Jones (1990) and Walther's (1996) hyperpersonal model of computer-mediated communication (CMC), the aim of the present paper is to examine whether different styles of selective positive self-presentation on Facebook are associated with higher levels of positive feedback from Facebook friends. We follow a 
two-study approach: In study 1 we investigate, building on questionnaire data, whether adolescents who present themselves in a positive manner by uploading profile pictures as well as posting status updates receive positive feedback more often in terms of the frequency of Likes. Using data from content analysis, we investigate in study 2 whether uploading different styles of profile pictures is related to a higher level of positive feedback in terms of number of Likes.

Our research extends past studies in the following ways. First, by pursuing a two-method approach, using data from online questionnaires as well as data from content analysis, we are able to balance the potential limitations associated with the interpretation of the findings for each type of data collection. For instance, social desirability may cause biases in self-reports, whereas by using content analysis we run a risk that not all potential information from everyone's Facebook profile is accessible due to privacy settings or that the obtained information cannot be systematically coded due to its complexity (Spies Shapiro \& Margolin, 2014).

Second, while most research examines the influence of Likes as a mediating variable between different aspects of SNS use and various psychological outcomes (Burrow \& Rainone, 2017; Frison \& Eggermont, 2015b) or its association with different psychological constructs (Burke, Marlow, \& Lento, 2010; Lee, Kim, \& Ahn, 2014), the basic question remains as to which kind of self-presentation among adolescents may result in positive feedback from the Facebook community. In line with other researchers (e.g., große Deters \& Mehl, 2013; Forest \& Wood, 2012), we refer to Likes as a direct positive social feedback.

Third, we examine not only quantitative aspects of self-presentation such as number of profile pictures, frequency of status updates, and number of friends (e.g., Oh, Ozkaya, \& LaRose, 2014) but also qualitative self-presentation behaviors on Facebook, such as different styles of profile pictures and status updates. Moreover, no study to our knowledge has yet offered a specific analysis of adolescents' self-presentation via status updates on Facebook.

Finally, unlike the majority of research on selfpresentation of Facebook (e.g., Yang \& Brown, 2016) we examine a non-college-age sample. In this way our research meets the challenges posed by researchers (Kim \& Lee, 2011; Spies Shapiro \& Margolin, 2014) to investigate ways of using SNSs that might benefit adolescents.

\section{Self-Presentation on Facebook}

Self-presentation is "the process of controlling how one is perceived by other people" (Leary, 1996, p. 2 ) and is a key element for relationship inception and development (Leary, 1996). Self-presentation has three important functions for individuals: It is an instrument to influence the impression they convey, it favors the development of positive emotions, and it affects individuals' self-esteem and identity construction (Leary, 1996). The primary goal is to receive social appreciation and validation (Leary, 2007; Schlenker \& Leary, 1982). Accordingly, research on strategic self-presentation in face-to-face contexts shows that individuals present themselves advantageously to make the best possible impression in an attempt to achieve valuable social goals (Schlenker \& Leary, 1982). Individuals whose self-presentation results in being perceived as competent, responsible or popular, for instance, will achieve greater social rewards than people who are perceived negatively, e.g., as irresponsible or socially incompetent (Schlenker \& Leary, 1982).

Based on behavioral observations in face-to-face interactions, Jones (1990) as well as Jones and Pittman (1982) developed a taxonomy that distinguishes five common self-presentational strategies that individuals commonly use. This taxonomy includes ingratiation, self-promotion, intimidation, exemplification, and supplication. Ingratiation is the most ubiquitous strategy in offline environments motivated by the need to get others to like oneself. It occurs when individuals use favors or flattery to obtain an attribution of likability from observers. Self-promotion is the second leading strategy. Self-promoters wish to convince others of their competence and intelligence. It occurs when people call attention to their accomplishments to be perceived as capable by observers. The strategy of intimidation is driven by the wish to be perceived as powerful, ruthless, and powerful. For instance, an employer might want to be viewed as powerful because he/she believes to increase the workers' productivity. Exemplification occurs when individuals attempt to create the impression that they are morally superior, virtuous, or righteous. A prototypical behavior for this strategy is to highlight the degree to which one has suffered poor treatment by others. Last, supplication occurs when people present their weaknesses or deficiencies to receive assistance from others and is motivated by the need to be perceived as helpless (Jones, 1990; Jones \& Pittmann, 1982). 
Several scholars have stressed the uniqueness of self-presentation in online environments. For instance, the hyperpersonal model of computermediated communication states that people have more control over their presented "self" in online contexts and therefore tend to selectively present themselves compared to face-to-face settings (Walther, 1996). In line with this model, findings in online self-presentation suggest that users present themselves positively on SNSs and especially on Facebook (Gonzales \& Hancock, 2011; Strano, 2008; Zhao, Grasmuck, \& Martin, 2008). This might be due to the fact that Facebook is an environment that promotes relationship formation, including self-disclosure and self-presentation, by providing multiple options for interactions with others. Expressing negativity on Facebook would violate its relationship-boosting goals (Forest \& Wood, 2012). Therefore, the strategies of intimidation, exemplification or supplication are not suitable in presenting oneself in an online environment such as Facebook.

Accordingly, the two positive self-presentational strategies of ingratiation and self-promotion might be most effective in eliciting positive feedback in virtual environments. In an online environment, an individual following the strategy of ingratiation could meet the need to be liked by others by presenting profile pictures in which she/he tries to look especially attractive ("posing") or fun-loving. Another possible strategy is presenting oneself in the company of friends or writing a status update that indicates that the user is having a great time together with others. In doing so, the profile owner can convey the impression of being socially integrated and therefore likeable. Transferring the strategy of self-promotion to an online context, a self-promoter could emphasize his or her skills and knowledge by uploading profile pictures in which he or she is engaging in a hobby or by making a personal statement that is meant to display intelligence, such as by expressing his or her attitude toward a socially relevant topic.

Among the various psychological phenomena that SNSs present, the possibilities of self-presentation are especially interesting for the period of adolescence due to two interrelated factors. First, adolescents have an enhanced need for self-presentation due to their developmental demands (Harter, 1999). A Facebook profile provides the opportunity to present oneself to a wide audience and to be socially rewarded for doing so (Valkenburg et al., 2006). Also, the need for self-presentation arises from the motive to develop meaningful relationships with others (Harter,
1999; Hartup, 1996). However, presenting oneself to others in a face-to-face context, especially to other peers, may lead to awkward or anxious feelings (Harter, 1999). Therefore, the second factor that explains the importance of investigating adolescents' online self-presentation arises from two features of CMC that can increase young individuals' control over their presented "self" in online environments: (a) the asynchronicity of communication, including selfpresentation, and (b) reduced visual and auditory cues (Valkenburg \& Peter, 2011; Walther, 1996). These two factors enable individuals to selectively present themselves (Van Ouytsel, Van Gool, Walrave, Ponmet, \& Peeters, 2016; Walther, 1996). Moreover, the ability to edit pictures gives individuals a further control opportunity on Facebook.

Self-presentation can be realized on Facebook in different ways, such as uploading pictures, posting status updates, or sharing personal information and preferences (Nadkarni \& Hofmann, 2012; Zhao et al., 2008). In our study, we focus on self-presentation via profile pictures (study 1 and study 2 ) and via status updates (study 1). We chose these two aspects based on their significance as found in previous research. Profile pictures are the most important instrument for self-presentation on SNSs (Strano, 2008; Wu, Chang, \& Yuan, 2015). The user's profile picture represents the individual on Facebook, appearing in search results for a new friend request and alongside every interaction. For instance, adolescents indicate that they look through the profile pictures on SNSs to find out more about a potential romantic partner, as this enables them to assess the personality of the user. Status updates, on the other hand, appear ideal for sharing what is happening in one's life (Köbler, Riedl, Vetter, Leimeister, \& Krcmar, 2010) as well as one's feelings and thoughts. They are short, continuously displayed messages users write (or "post") on their profile pages prompted by the question "What are you doing right now?" on one's Facebook page. Status updates were also seen as the most important source of information about a potential romantic partner (Van Ouytsel et al., 2016).

Experimenting with different self-presentational strategies is most important during adolescence (Valkenburg, Schouten, \& Peter, 2005) due to the increase of identities that vary as a function of different environments in which young people participate (Harter, 1998). The way in which adolescents choose to present themselves in SNSs may be a key part of their identity development (Reich, Subrahmanyam, \& Espinoza, 2012). Altered self-presentation seems 
to be less frequent than initially thought, and people tend to present their actual personality, rather than providing misinformation (Back et al., 2010; Bargh, McKenna, \& Fitzsimons, 2002; Borca, Bina, Keller, Gilbert, \& Begotti, 2015; Metzler \& Scheithauer, 2015), perhaps because online friends know the user offline and would thus contradict a user's inaccurate or exaggerated self-presentation by giving negative feedback (Ellison et al., 2007; Lenhart \& Madden, 2007; Pempek, Yermolayeva, \& Calvert, 2009; Subrahmanyam, Reich, Waechter, \& Espinoza, 2008; Van Zalk, Van Zalk, Kerr, \& Stattin, 2014). Hence it is crucial to investigate adolescents' self-presentation on SNSs. Nevertheless, research on strategic selfpresentational behaviors in adolescence is rare.

\section{Positive Feedback on Social Networking Sites}

Social feedback on SNSs can be provided in different ways. First, users can write each other private messages and react to other users' self-presentational behaviors in a comprehensive manner. Second, there are more popular alternatives for providing social feedback on SNSs that are also publicly accessible for every other member of the Facebook community: writing a comment and clicking the Like button. While the first is text-based and thus more elaborate and comparable to writing a private message, giving a Like requires less effort as it is a lightweight, one-click feedback action (Scissors, Burke, \& Wengrovitz, 2016). The fact that more elaborate feedback actions are less popular than clicking the Like button is reflected in their usage numbers: 19\% of Facebook users send private messages to their Facebook friends on a daily basis, $31 \%$ comment on other users' photos on a daily basis, and $44 \%$ like content posted by their friends at least once a day (Smith, 2014). A closer look into a representative German adolescent sample reveals that the use of the Like button is one of the most popular activities on SNSs: $64 \%$ of adolescents aged 14-19 use it regularly (Feierabend, Plankenhorn, \& Rathgeb, 2015).

Besides the popularity of using Likes, the question about the meaning of Likes still remains. A recent study by Hong and colleagues (2017) argues that liking on Facebook can be perceived as a form of online gift giving. Their results suggest that the more gifts individuals receive, the more they signal their positive image to others. Also, demographic characteristics such as age and gender are related to the frequency of getting Likes.
A Like, expressed on Facebook through clicking a button with a "thumb up" symbol, could also be seen as a cue for social affirmation or sympathy equivalent to the concept of liking in the offline world. For instance, a recent study found that the Like feature is related to building social capital and to bonding (Lee et al., 2014). Also, adolescent Facebook users indicated that they like pictures and status updates from others in order to express romantic interest (Van Ouytsel et al., 2016).

Receiving Likes can also be interpreted as a signal for social acceptance within a user's social environment. Individuals' self-esteem was found to increase as a function of the number of Likes received on their Facebook pictures (Burrow \& Rainone, 2017). Additionally, Scissors and colleagues (2016) argue that Likes are social cues expressing social appropriateness or social acceptance. Examining individuals' attitudes and behaviors related to receiving Likes on SNS, they found that users indicate that Likes represent signals of like-mindedness or support.

Expanding on this notion, it is plausible to perceive Likes as a kind of social support among adolescents, as they are digital natives (Prensky, 2001). While there are many different forms of social support (e.g., Cohen, Mermelstein, Kamarck, \& Hoberman, 1985), two types seem to be the most relevant on SNSs: companionship support, in which interactions with others provide support, and esteem support, which imparts a sense of value and validates the individual (Braithwaite, Waldron, \& Finn, 1999; Eastin \& LaRose, 2005; Oh et al., 2014). Whereas companionship support can be given on Facebook by inviting a friend to a group within Facebook, for example, Likes can express esteem support. As social support is important in adolescence (Arnett, 1999) and peers gradually take on a central role in the relational network (Furman \& Buhrmester, 1993; Helsen et al., 2000), any form of social support online may contribute to mental health in adolescence (Frison \& Eggermont, 2015a).

Even at a neurological level, researchers found evidence for the significant role of Likes as a form of positive feedback on SNSs. Meshi, Morawetz, and Heekeren (2013) found that the processing of self-relevant gains in reputation in the left nucleus accumbens predicted the intensity of Facebook use across young adults. This result was specific to positive feedback in terms of Likes on Facebook for the self-presentation via profile pictures to observing positive social feedback for others (Meshi et al., 2013). Accordingly, Sherman and colleagues 
(2016) found that adolescents who viewed photos of themselves on SNSs that had received more likes demonstrated greater activation of neural regions involved in reward processing such as nucleus accumbens (Sherman, Payton, Hernandez, Greenfield, \& Dapretto, 2016).

In sum, given the high frequency and the popularity of the use of Likes as well as their unique positive value, it is important to examine the relationships between adolescents' positive self-presentation on Facebook and the frequency as well as the magnitude of receiving Likes.

Unfortunately, research on social feedback to online self-presentation in adolescence is limited. Frison and Eggermont (2015b) found a direct relationship between active Facebook use (e.g., posting pictures) and positive responses (e.g., Likes). Nevertheless they did not take either the style of pictures or the style of status updates into account. Moreover their study was solely based on questionnaire data.

To fill this gap in the literature, the current study examines which kind of positive self-presentational behaviors on Facebook are associated with positive feedback measured as received Likes from one's Facebook friends. Based on Jones' (1990) categorization of self-presentational strategies, the following hypothesis is proposed: The self-presentational strategy "ingratiation" will elicit more positive feedback from one's Facebook friends than the selfpresentational strategy "self-promotion" $($ H1).

\section{Gender Differences in Self-Presentation and in Eliciting Positive Responses from one's SNS Network}

In general, girls have been found to communicate more with their friends on Facebook (Reich et al., 2012), disclose more information on SNSs (Valkenburg \& Peter, 2007; Valkenburg, Sumter, \& Peter, 2011) and engage in internet-based identity experiments for self-exploration more often than boys do (Valkenburg et al, 2005). In contrast, boys have been found to use SNSs more often to meet new people, and to talk about sports or play videogames (Davis, 2012; Laghi et al., 2013; Lenhart \& Madden, 2007).

Based on these studies emphasizing gender-related differenced in online communication and in SNSs usage in general, it can be assumed that females and males also differ in their self-presentation on SNSs. Corresponding to findings in sex differences in selfpresentation in everyday interactions men presented themselves more favorably on matters related to competence while women chose to present themselves more positively on interpersonal and socio-emotional attributes (Leary et al., 1994). Also, men's photos in online environments have been found to accentuate status (using objects of formal clothing) and risk taking (outdoor settings) (Tifferet \& Vilnai-Yavetz, 2014), sport activities and independence (Dominick, 1999). Moreover, men chose to upload more profile pictures that show the fullbody, probably in an attempt to demonstrate their masculinity (Haferkamp, Eimler, Papadakis, \& Kruck, 2012) and displayed more self-promotional content in the „About

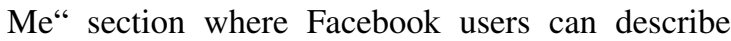
themselves in their own words (Mehdizadeh, 2010).

In contrast, women have been found to engage in self-presentational behavior on SNSs more intensively in general by uploading profile pictures, writing status updates (Rui \& Stefanone, 2013) and pursuing the strategies of ingratiation as well as selfpromotion more often than men (Bareket-Bojmel, Moran, \& Shahar, 2016). Moreover, females' photos accentuated familial and other social relations, emotional positive expressions (eye contact, smile intensity) (Mazur \& Kozarian, 2010; Strano, 2008; Tifferet \& Vilnai-Yavetz, 2014), physical attractiveness (Manago, Graham, \& Greenfield, 2008) and showed primarily their faces (Haferkamp et al., 2012). Also the findings of Oberst, Renau, Chamarro, and Carbonell (2016) indicated that adolescent girls present themselves in a more stereotypical way on Facebook than boys by adorned photos of their physical appearance, though adolescent users present themselves in general in a less gender stereotypical way. Based on the research discussed above we developed the following research question: are there gender differences in the way adolescents choose to present themselves on Facebook (RQ1)?

With respect to gender differences in eliciting positives feedback in terms of Likes on Facebook the findings are mixed. Hong and colleagues (2017) found that females significantly gave and received Likes significantly with higher frequencies than men did. Also adolescent girls were found to receive a higher number of Likes on Facebook compared to adolescent boys (Metzler \& Scheithauer, 2017). One explanation for these gender differences is probably a direct result of the way females and males choose to present themselves as mentioned above. As females more often chose to highlight their social relationships on SNSs (Mazur \& Kozarian, 2010), as well as to promote a happy and fun-loving impression of 
themselves (Strano, 2008; Tifferet \& Vilnai-Yavetz, 2014), they might be perceived as more positive and likeable and therefore receive positive feedback with a higher frequency. Nevertheless, the majority of studies did not find any gender differences in the frequencies of either giving or receiving positive feedback on Facebook (Bareket-Bojmel et al., 2016; Burrow \& Rainone, 2017; Frison \& Eggermont, 2015). To shed light on this relationship, we investigate the following research question: are there gender differences in eliciting positive feedback from one's Facebook friends (RQ2)?

\section{Methods \\ Study 1 - Questionnaire Data}

\section{Participants and Procedure}

As part of a broader research project, the URL of the online questionnaire was distributed from September 2013 to January 2014 via two channels: the first was spickmich.de, a German social networking site, and the second was different Facebook groups dealing with the interests of adolescents. 869 participants retrieved the questionnaire. We ensured no repeated participation by turning off the "multiple responses" option for our questionnaire on SurveyMonkey. All participants gave informed consent as approved by the Ethics Board of Freie Universität Berlin, Department of Education and Psychology. The participants were also informed that they are allowed to ask for the deletion of their answers at any time as well as that all answers would be treated anonymously.

The questionnaire sample consisted of 703 participants (71.7\% female) with a mean age of 15.76 years $(S D=1.08)$, after excluding participants who did not match the age range (14-17 years), who did not complete the questionnaire or who answered unreliably by speeding through the questionnaire. Most (47.1\%) were attending college-preparatory school, $18.5 \%$ were attending vocational school, $5 \%$ gen$\mathrm{eral} / \mathrm{mixed}$ school - all of which are different forms of German secondary schools $-24 \%$ were attending other forms of school; $5.4 \%$ reported not going to school anymore.

\section{Measures}

\section{Number of Facebook Friends}

The Number of Facebook friends was measured by asking how many people were listed as "friends" in participants' Facebook profile. Participants answered on an open response scale.

\section{Number of Profile Pictures and Status Updates}

Quantitative self-presentation was measured using two items: number of profile pictures, requiring openended responses, and frequency of status updates, which was elicited by asking the respondents to indicate how often they posted something on Facebook. Item responses were never to more than 10 times per day, week, month, or year. The frequency of status updates on Facebook was subsequently recoded as frequency of the user's Facebook status updates per month.

\section{Positive Self-Presentation}

Positive self-presentation through profile pictures and through status updates was measured using five items each. Self-presentation following an ingratiating style was assessed by the following items: "How often do you use a profile picture that shows you with friends?", “... that shows you striking a 'pose'?", ... that shows you making a funny mimic/gesture?", "How often do you write a status update that says that you spent time with friends?”, “... that says that you experienced something nice?", and “... that says that you are happy?". The self-promotional style was operationalized through the following items: "How often do you use a profile picture that shows you engaging in a hobby?", "How often do you write a status update that says that you were successful at something?", and "... that expresses your opinion on a special topic?". All items had five response categories, ranging from 1 (never) to 5 (very often). The reliability (Cronbach's Alpha) was 0.644 for self-presentation via profile pictures and 0.806 for self-presentation via status updates.

\section{Positive Feedback}

Positive feedback in terms of the frequency of receiving Likes for profile pictures as well as for status updates was measured for each using a fivepoint scale ranging from 1 (never) to 5 (always). The respondents evaluated the following items: "How often do you get Likes for your profile pictures?" and "How often do you get Likes for your status updates?". For descriptive statistics and zero-order correlations see Table 1. 


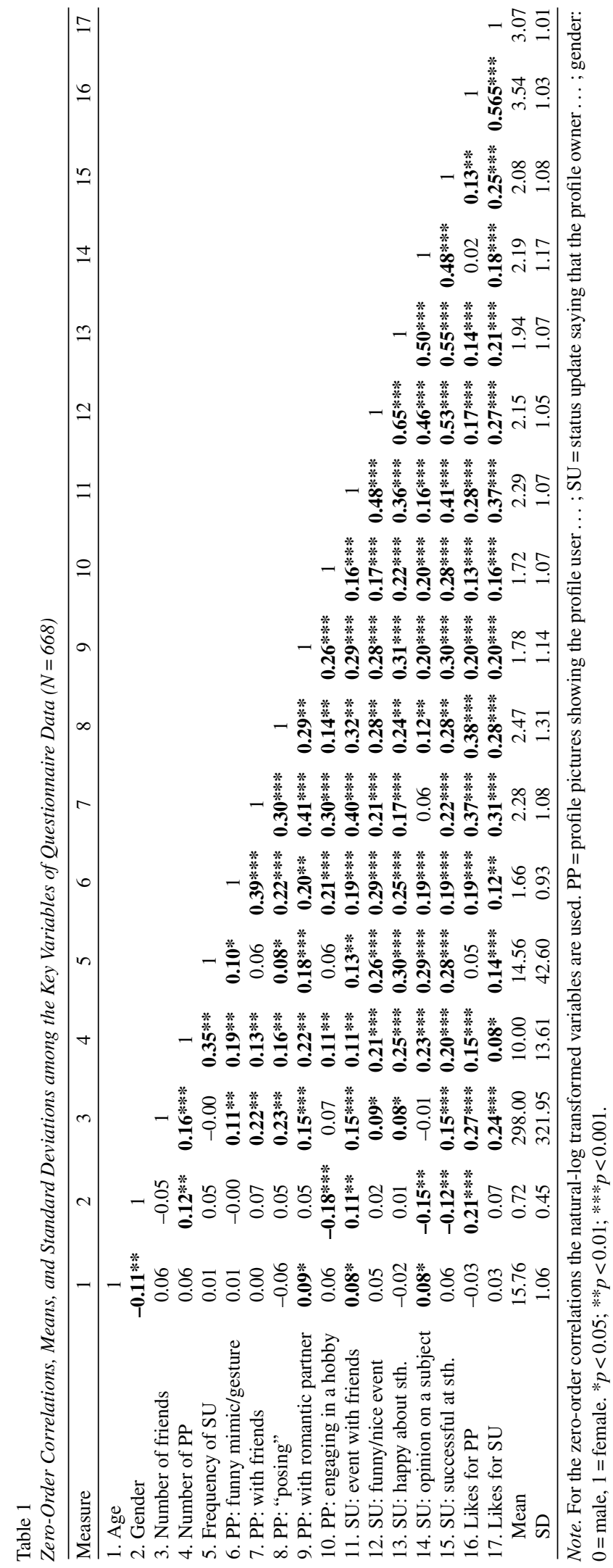




\section{Strategy of Analysis}

Preliminary analyses were conducted to ensure no violation of the assumptions of statistical analyses. Firstly, the sample size was deemed adequate (Tabachnick \& Fidell, 2007). Although there are still divergences from normality, this can be neglected when using multiple regressions in case of a sufficient sample size (Cohen, Cohen, West, \& Aiken, 2003, p. 120). Divergences of homoscedasticity assumptions are also not severe (Tabachnick \& Fidell, 2007, p. $85)$. The analyses of the tolerance values and the corresponding VIF values of all hierarchical multiple regressions showed that multicollinearity was unlikely to be a problem. For all statistical analyses, IBM SPSS Statistics 22 was used.

Preliminary analyses were conducted to examine whether there are age or gender differences in the way adolescents present themselves on Facebook.

To answer the research question we used the self-reported data set $(N=694)$. We ran hierarchical multiple regression analyses with number of Likes for profile pictures (model 1) and number of Likes for status updates (model 2) as dependent variables, and with three blocks each comprising three sets of independent variables. Block 1 includes age and gender. We chose to control for these items because age and gender might affect the kind of self-presentation and the network size (number of friends) and therefore the number of potential Likes for one's Facebook activities. As previous research in young adults has shown that the network size influences the extent of positive response on SNSs (Kim \& Lee, 2011; Manago et al., 2012; Nabi, Prestin, \& So, 2013; Oh et al., 2014), it seems reasonable furthermore to control for the number of participant's Facebook friends. Finally, we controlled for the number of profile pictures and frequency of status updates in general to demonstrate that not only the mere usage, but also the style is associated with positive feedback.

Accordingly, block 2 includes number of Facebook friends and the number of profile pictures (model 1), and the frequency of status updates (model 2) as independent variables. Block 3 additionally contains the five self-presentational strategy items relating to profile pictures (model 1) and the five self-presentational strategy items relating to status updates (model 2). The quantitative and qualitative items were entered in different blocks based on the assumption that not only the quantity of self-presentation, but also the quality of self-presentation predicts positive feedback.
As number of friends and number of profile pictures are count variables that have a floor of zero and no ceiling, and the variable frequency of status updates has a large range of answer options, any distribution drawn from such populations would be expected to be positively skewed and thick-tailed. Indeed, number of Facebook friends, number of profile pictures, and frequency of status updates revealed both skewness and kurtosis. Because this violates the normality and homoscedasticity assumptions of regression models, we normalized the distributions using a natural-log transformation (Cohen et al., 2003). As the transformations showed much improved skewness and kurtosis, we employed the natural-log transformed variable in our analyses.

\section{Results - Study 1 - Questionnaire Data}

The results of the preliminary analyses of age and gender differences in the way adolescents present themselves on Facebook revealed a significant multivariate effect for age, Pillais' Trace $F(30,1968)=1.544, p=0.03, \eta^{2} \mathrm{p}=0.069$. The subsequently analyses showed that adolescents aged 17 were posting most frequently about spending time with friends. Gender was also found to have a significant effect, Pillais' Trace $F(10,654)=6.995$, $p=0.00, \eta^{2} \mathrm{p}=0.097$. Subsequently univariate analysis revealed that boys scored significantly higher on the number of profile pictures showing the user engaging in a hobby as well as posting about one's opinion on a subject and being successful at something. In contrast, girls posted more frequently about spending time with their friends.

In the first step of the hierarchical multiple regressions with Likes for styles of profile pictures as dependent variable, two control predictors were entered: age and gender. This model was statistically significant $(\mathrm{F}[2,679]=15.44 ; p>0.000)$ and explained $4.3 \%$ of variance. After entering number of Facebook friends and number of profile pictures at step 2, the total variance explained by the model as a whole was $21.4 \%(\mathrm{~F}[2,677]=46.07 ; p<0.000)$. With the addition of the different styles of profile pictures in step 3, the model explained $32.1 \%$ (F[9, $672]=35.28 ; p<0.000$ ) of variance in positive feedback. Therefore the quantitative variables as well as different self-presentational styles together did predict positive feedback better than the demographic variables alone. The results are provided in Table 2.

Using Likes for styles of status updates as dependent variable, age and gender were entered in the 
Table 2

Hierarchical Regression for Likes for the Style of Profile Pictures $(N=682)$

\begin{tabular}{|c|c|c|c|c|c|c|}
\hline Predictor & $\mathrm{R}$ & $R^{2}$ & $\Delta R^{2}$ & $B$ & SE & $b$ \\
\hline Step 1: Control variables & 0.209 & $0.043 * * *$ & 0.043 & & & \\
\hline Age & & & & -0.009 & 0.037 & -0.009 \\
\hline Gender & & & & 0.482 & 0.088 & 0.207 \\
\hline Step 2: Quantitative variables & 0.463 & $0.214 * * *$ & 0.170 & & & \\
\hline Age & & & & -0.062 & 0.034 & -0.064 \\
\hline Gender & & & & 0.400 & 0.081 & $0.172 * * *$ \\
\hline Number of profile pictures & & & & 0.518 & 0.102 & $0.188 * * *$ \\
\hline Number of friends & & & & 0.756 & 0.086 & $0.318 * * *$ \\
\hline Step 3: Qualitative variables & 0.566 & $0.321 * * *$ & 0.107 & & & \\
\hline Age & & & & -0.031 & 0.032 & -0.032 \\
\hline Gender & & & & 0.399 & 0.078 & $0.172 * * *$ \\
\hline Number of profile pictures & & & & 0.305 & 0.100 & $0.110 * *$ \\
\hline Number of friends & & & & 0.527 & 0.083 & $0.222 * * *$ \\
\hline \multicolumn{7}{|c|}{ Profile Pictures showing the profile owner... } \\
\hline$\ldots$ with a funny mimic/gesture & & & & 0.000 & 0.039 & 0.000 \\
\hline$\ldots$ with friends & & & & 0.204 & 0.038 & $0.211 * * *$ \\
\hline ... "posing" & & & & 0.182 & 0.028 & $\mathbf{0 . 2 3 0} * * *$ \\
\hline ... with his/her romantic partner & & & & -0.029 & 0.033 & -0.031 \\
\hline$\ldots$ engaging in a hobby & & & & 0.038 & 0.034 & 0.039 \\
\hline
\end{tabular}

Note. ${ }^{*} p<0.05 ; * * p<0.01 ; * * * p<0.001$.

first step. This model was statistically not significant $(\mathrm{F}[2,665]=1.91 ; p=0.149)$. After entering number of Facebook friends and frequency of status updates at step 2, the total variance explained by the model as a whole was $37.0 \%(F[4,663]=26.36 ; p<0.000)$. With the addition of the different styles of status updates in step 3, the model explained $45.4 \%(F[9,658]=18.98$; $p<0.000)$ of variance in positive feedback. Therefore, the quantitative variables as well as the different self-presentational styles together did predict positive feedback better than the demographic variables alone. The results are provided in Table 3 .

\section{Study 2 - Content Analysis}

\section{Participants and Procedure}

In addition to completing the online questionnaire, participants were asked at the end of the questionnaire to add our "research profile" as a friend on Facebook. We then accessed the profiles, the profile pictures, and the number of friends, among other things, of 144 adolescents over a period of two weeks. One participant had to be excluded as an extreme outlier on nearly all variables as she happened to be a "Facebook celebrity". The final sample consisted of 143 participants $(63.6 \%$ female) with a mean age of 15.72 years $(\mathrm{SD}=1.13)$. Most $(47.6 \%)$ were attending collegepreparatory school, $18.2 \%$ vocational school, $3.5 \%$ general/mixed school. $25.8 \%$ were attending other forms of schools and $4.9 \%$ reported not going to school anymore.
All participants gave informed consent as approved by the Ethics Board of Freie Universität Berlin, Department of Education and Psychology. The participants were also informed that they are allowed to ask for the deletion of their answers at any time as well as that all answers would be treated anonymously.

\section{Measures}

The coding system was based on the system of Krämer and Winter (2008) that was developed for a German social network (StudiVZ). We further refined a comprehensive coding system to match to our research question and Facebook. The coding was conducted by a student assistant and the first author, and tested with a preliminary study of ten Facebook profiles (mixed in age and gender). In the following only measures relevant to the present research questions will be described.

Quantitative Variables: Number of Profile Pictures, Number of Facebook Friends and Positive Feedback

The following items displayed on the profile page of the user were recorded: number of Facebook friends, number of profile pictures, and positive feedback coded in terms of number of Likes the users received for their profile pictures. For the calculation of inter-rater reliability, we used means of Cohen's $\kappa$. All results are significant and have a coefficient of 1.0. 
Table 3

Hierarchical Regression for Likes for the Style of Status Updates $(N=668)$

\begin{tabular}{|c|c|c|c|c|c|c|}
\hline Predictor & $\mathrm{R}$ & $R^{2}$ & $\Delta R^{2}$ & $B$ & SE & $b$ \\
\hline Step 1: Control variables & 0.076 & 0.006 & 0.006 & & & \\
\hline Age & & & & 0.036 & 0.037 & 0.038 \\
\hline Gender & & & & 0.157 & 0.088 & 0.070 \\
\hline Step 2: Quantitative variables & 0.370 & $0.137 * * *$ & 0.131 & & & \\
\hline Age & & & & 0.009 & 0.035 & 0.009 \\
\hline Gender & & & & 0.153 & 0.082 & 0.068 \\
\hline Frequency of status updates & & & & 0.434 & 0.061 & $0.258 * * *$ \\
\hline Number of friends & & & & 0.656 & 0.088 & $0.270 * * *$ \\
\hline Step 3: Qualitative variables & 0.454 & $0.206 * * *$ & 0.069 & & & \\
\hline Age & & & & -0.017 & 0.034 & -0.018 \\
\hline Gender & & & & 0.125 & 0.081 & 0.055 \\
\hline Frequency of status updates & & & & 0.196 & 0.072 & $0.116 * *$ \\
\hline Number of friends & & & & 0.539 & 0.088 & $0.222 * * *$ \\
\hline Status updates saying that the profile owner. & & & & & & \\
\hline$\ldots$ is spending time with friends & & & & 0.233 & 0.040 & $0.245 * * *$ \\
\hline$\ldots$ had experienced something funny or nice & & & & 0.049 & 0.049 & 0.050 \\
\hline$\ldots$ is happy or glad about something & & & & -0.039 & 0.048 & -0.041 \\
\hline$\ldots$ has an opinion on a subject & & & & 0.075 & 0.039 & 0.087 \\
\hline ... was successful at something & & & & 0.031 & 0.044 & 0.033 \\
\hline
\end{tabular}

Note: $* p<0.05 ; * * p<0.01 ; * * * p<0.001$.

\section{Positive Self-Presentation}

Self-presentation through different styles of profile pictures displayed on the profile page was recorded. The self-presentational strategy "ingratiation" was operationalized by the following item: profile pictures that show the profile owner striking a 'pose' (e.g. striking a "model" pose or trying to look especially attractive), making a funny mimic/gesture, and in company of friends. Profile pictures that show the profile owner engaging in a hobby (e.g., presenting the user in the team uniform of his/her football club) and profile pictures that show the profile owner expressing his attitude towards a special topic (e.g., presenting a "anti-nuclear-power sun" besides the face of the profile owner as a symbol against the use of nuclear energy in Germany) are classified as self-promotion. For the calculation of inter-rater reliability we used Pearson correlations. All coefficients were significant and varied between 0.997 (for "posing") and 1.00 .

For descriptive statistics and zero-order correlations see Table 4.

\section{Strategy of Analysis}

In accordance with the strategy of analysis of study 1 , preliminary analyses were conducted to ensure no violation of the assumptions of statistical analyses. In addition, preliminary analyses were conducted to examine whether there are age or gender differences in the way adolescents present themselves on Facebook.

As all variables were count variables due to the nature of data collection with a (theoretical) floor of zero and no ceiling, we normalized the distribution using natural-log transformation (Cohen et al., 2003) as in study 1 . The natural-log transformation showed much improved skewness and kurtosis for all the variables. We thus employed the natural-log transformed variables in the analysis.

\section{Results - Study 2 - Content Analysis}

The results of the preliminary analyses of age or gender differences in the way adolescents present themselves on Facebook using data from content analysis revealed no significant multivariate effect for age, Pillais' Trace $\mathrm{F}(15,408)=1.393, p=0.15$, $\eta^{2} \mathrm{p}=0.146$. Gender was found to have a significant effect, Pillais' Trace $\mathrm{F}(5,134)=2.527, p=0.03$, $\eta^{2} \mathrm{p}=0.086$. Follow-up univariate analysis revealed that girls scored significantly higher on the number of profile pictures showing the user spending time with friends as well as striking a pose.

Table 5 presents the hierarchical multiple regression model of Likes for the style of the profile pictures. In the first step the control predictors age and gender were entered. This model was statistically significant, $\mathrm{F}(2,119)=3.701, p=0.028$. Gender was found to be positively associated with positive feedback with girls eliciting more Likes. Introducing the 
Table 4

Zero-Order Correlations, Means, and Standard Deviations among Key Variables of Data from Content Analysis $(N=143)$

\begin{tabular}{|c|c|c|c|c|c|c|c|c|c|c|}
\hline & 1 & 2 & 3 & 4 & 5 & 6 & 7 & 8 & 9 & 10 \\
\hline 1. Age & - & & & & & & & & & \\
\hline 2. Gender & -0.15 & - & & & & & & & & \\
\hline 3. Number of profile pictures & 0.03 & $0.22 * *$ & - & & & & & & & \\
\hline 4. Number of friends & 0.17 & -0.09 & 0.15 & - & & & & & & \\
\hline 5. PP: with (an)other person(s) & $0.24 * *$ & 0.16 & $0.41 * * *$ & $0.23 *$ & - & & & & & \\
\hline 6. PP: "posing" & 0.03 & $0.21 *$ & $0.67 * * *$ & $0.34 * * *$ & $0.18 *$ & - & & & & \\
\hline 7. PP: funny mimic/gesture & $-0.16^{*}$ & 0.10 & $0.44 * * *$ & -0.03 & 0.04 & $0.33 * * *$ & - & & & \\
\hline 8. PP: engaging in a hobby & 0.08 & -0.03 & $0.32 * * *$ & 0.04 & $0.32 * * *$ & 0.08 & 0.09 & - & & \\
\hline 9. PP: making a personal statement & -0.01 & 0.14 & $0.52 * * *$ & -0.02 & $0.21 *$ & $0.33 * * *$ & $0.39 * * *$ & $0.23 * *$ & - & \\
\hline 10. Number of Likes & 0.13 & $0.18 *$ & $0.58 * * *$ & $0.70 * * *$ & $0.40 * * *$ & $0.65 * * *$ & $0.24 * *$ & $0.23 * *$ & $0.23 * *$ & - \\
\hline$M$ & 15.72 & 0.63 & 10.97 & 332.91 & 0.97 & 3.44 & 0.47 & 0.45 & 0.27 & 160.40 \\
\hline$S D$ & 1.12 & 0.48 & 17.30 & 379.09 & 1.91 & 5.84 & 1.00 & 1.12 & 0.91 & 257.01 \\
\hline
\end{tabular}

Note. For the zero-order correlations the natural-log transformed variables are used; $\mathrm{PP}=$ profile picture, showing the profile owner...; gender: $0=$ male, $1=$ female. ${ }^{*} p<0.05 ; * * p<0.01 ; * * * p<0.001$.

number of profile pictures and number of Facebook friends at step 2, the change in $\mathrm{R}^{2}$ was significant, $\mathrm{F}(4$, $117)=73.078, p<0.000$. Number of profile pictures and number of friends were positively associated with positive feedback. With the addition of the different styles of the profile pictures in step 3 , the change in $\mathrm{R}^{2}$ was significant, $\mathrm{F}(9,112)=41.799, p<0.000$. Both presenting oneself with others and striking a pose are positively correlated with the number of Likes, whereas the number of pictures was no longer significant.

\section{Discussion}

The present study investigated which kind of positive self-presentational behaviors are associated with positive feedback from Facebook friends. In particular, presenting oneself in the company of others, trying to look especially attractive in the profile picture, and posting status updates about spending time with friends appear to be the most successful strategies for receiving positive feedback. Interestingly, both data from the online questionnaire as well as data from content analysis led to very similar results. These findings highlight the beneficial effects of adolescents' positive self-presentation on Facebook.

In line with previous research among adults (Hong et al., 2017) and adolescents (Metzler \& Scheithauer, 2017), gender was found to be a significant predictor using questionnaire data as well as data from content analysis, with girls getting more Likes for their self-presentation through profile pictures on Facebook. This finding may be explained by the fact that girls tend to present themselves as socially integrated to a greater extent. Indeed, our preliminary analyses revealed that girls wrote more frequently as well as posted pictures more frequently that showed them spending time with friends or striking a pose, pursuing a self-presentational strategy of ingratiation. This finding is also in line with the results of Mazur and Kozarian (2010) that girls received more reactions and replies on their online blog entries (short text messages similar to status updates on Facebook).

The analysis of gender differences also revealed that boys were more likely to pursue the strategy of self-promotion by, for example, posting about having success in life or presenting pictures showing the user engaging in a hobby. These results may also hold as an explanation for the insignificance of "gender" when entering as a predictor for "Likes for the styles of status updates" as the dependent variable. Writing status updates seems to be an equally good tool when pursuing the strategy of self-promotion as well as the strategy of self-ingratiation on Facebook whereas posting profile pictures seems most appropriate for the strategy of self-ingratiation. Nevertheless, multiple regressions did not reveal an association between self-promotional strategies and positive feedback.

Taken together, as in previous studies, females were found to be more interested in the social aspects of SNSs in general (Bonetti, Campbell, \& Gilmore, 2010; Dominick, 1999; Lenhart \& Madden, 2007; Tifferet \& Vilnai-Yavetz, 2014; Valkenburg \& Peter, 2007; Valkenburg et al., 2011) and using an "ingratiation" style of positive self-presentation in particular, so they might choose more carefully which impression they convey with the positive consequence of getting more positive feedback.

Controlling for the number of Facebook friends, our results show that this variable is a strong predictor for the number of Likes for profile pictures (study 
Table 5

Hierarchical Regression for Likes for the Style of Profile Pictures $(N=122)$

\begin{tabular}{|c|c|c|c|c|c|c|}
\hline Predictor & $\mathrm{R}$ & $R^{2}$ & $\Delta R^{2}$ & $B$ & SE & $b$ \\
\hline Step 1: Control variables & 0.242 & 0.059* & 0.059 & & & \\
\hline Age & & & & 0.086 & 0.058 & 0.133 \\
\hline Gender & & & & 0.342 & 0.138 & $0.223 *$ \\
\hline Step 2: Quantitative variables & 0.845 & $0.714 * * *$ & 0.656 & & & \\
\hline Age & & & & 0.011 & 0.033 & 0.016 \\
\hline Gender & & & & 0.273 & 0.079 & $0.178 * *$ \\
\hline Number of profile pictures & & & & 0.777 & 0.098 & $0.406 * * *$ \\
\hline Number of friends & & & & 1.213 & 0.095 & $0.654 * * *$ \\
\hline Step 3: Qualitative variables & 0.878 & $0.771 * * *$ & 0.056 & & & \\
\hline Age & & & & -0.005 & 0.031 & -0.007 \\
\hline Gender & & & & 0.222 & 0.074 & $0.145 * *$ \\
\hline Number of profile pictures & & & & 0.259 & 0.146 & 0.136 \\
\hline Number of friends & & & & 1.042 & 0.095 & $0.561 * * *$ \\
\hline \multicolumn{7}{|c|}{ Profile pictures showing the profile owner... } \\
\hline$\ldots$ (an)other person(s) & & & & 0.354 & 0.146 & $0.131 *$ \\
\hline$\ldots$,posing & & & & 0.549 & 0.123 & $0.298 * * *$ \\
\hline ... making a funny mimic/gesture & & & & 0.210 & 0.200 & 0.059 \\
\hline ... engaging in a hobby & & & & 0.343 & 0.182 & 0.094 \\
\hline ... making a personal statement & & & & -0.097 & 0.244 & -0.022 \\
\hline
\end{tabular}

Note. $* p<0.05 ; * * p<0.01 ; * * * p<0.001$.

2) as well as for the frequency of Likes for profile pictures and status updates (study 1). Therefore our results are in line with previous research on (young) adults showing a positive association between the network size and different forms of social support (Kim \& Lee, 2011; Manago et al., 2012; Nabi et al., 2013; Oh et al., 2014; Ybarra, Mitchell, Palmer, \& Reisner, 2015). This may not be a surprising result but a very encouraging one, considering that Facebook friends are not hard to get but seem to provide a beneficial effect (Kim \& Lee, 2011), especially against the background that having a single friend offline is associated with an increased self-esteem in the period of adolescence (Bishop \& Inderbitzen, 1995).

The number of profile pictures (study 1 and study 2) as well as the frequency of status updates (study 1) were significant predictors for positive feedback at step two in all models. Nevertheless, the contribution of the different self-presentational styles did help predict positive feedback better.

Examining positive self-presentation through profile pictures revealed that presenting oneself in the company of others is positively associated with positive feedback. This may hold for several reasons. First, as adolescents have a particular need for maintaining and emphasizing social relationships (Ellison et al., 2007; Nadkarni \& Hofmann, 2012; Spies Shapiro \& Margolin, 2014), presenting oneself in a social situation seems to be very useful in generating positive reactions. Second, this may elicit more attention in general because there are different people of potential interest in the picture. By "tagging" (linking the name of another user with a picture) other people in the picture, users can also increase the reach of their profile picture on Facebook, i.e. more people will see and respond to it.

The finding is also in line with other studies revealing that adolescents are more likely to choose photos that show the user with others to emphasize their offline social connections online and by doing so express their notions of personal identity through relationships (Livingstone, 2008; Strano, 2008). Sas and colleagues (2009) described two other beneficial consequences of presenting positive social moments in one's life on Facebook in the context of the Capitalization Theory. According to this theory, presenting positive emotions and experiences on SNSs enables the user to remember this special moment in life again and in doing so re-experience it.

Presenting oneself in a "pose" was found to have the strongest association with positive feedback. "Posing" in the sense of trying to look especially appealing in the profile picture seems to pay off as Facebook friends acknowledge the effort. This finding has an interesting implication, as adolescents could be encouraged to carefully choose and possibly edit a profile picture to appear likeable.

As presenting oneself with friends and striking a pose can be assigned to the self-presentational strategy of ingratiation (Jones, 1990), our findings are in line with research in young adults' selfpresentation on personal webpages showing that 
ingratiation is the most common self-presentational strategy (Dominick, 1999). Nevertheless, profile pictures that show the user making a funny face or gesture, also a type of ingratiation, did not predict positive feedback. One explanation could be that the owner is in some cases not perceived as funny, but as silly or trying too hard to appear likeable. Also the small number of pictures showing the user making a funny gesture or facial expression (study 2) as well as the less frequent use of this kind of profile picture (study 1) could have caused these results.

The examination of self-presentation through status updates reveals that only posting about spending time with friends was associated with positive feedback. Presenting oneself in the company of others may elicit Likes more frequently because others are happy for the user and appreciate the user for sharing these moments with others. All other selfpresentational styles in status updates did not predict positive feedback.

Our findings contribute to the existing literature in two ways. First and foremost, our study reveals what kind of self-presentational styles adolescents favor on Facebook by linking the theoretical framework of self-presentational strategies by Jones (1990) to certain behaviors in an online environment. As selfpresentation is an important skill in the process of adolescents' psychosocial development, namely the development and maintenance of social relationships (Harter, 1999; Hartup, 1996; Valkenburg \& Peter, 2011), it is important to understand what kind of selfpresentational styles young people prefer on online communication platforms to achieve these developmental goals. The data thereby suggests a tentative answer to the general question why Facebook enjoys such a great popularity among young people. One's personal Facebook page, including one's profile pictures and status updates, seems to primarily serve a "social linkage" function. By using an ingratiation self-presentational style adolescents are able to foster and to maintain supportive relationships with other peers. Accordingly, a recent study revealed the need to belong could positively predict adolescents' authentic self-presentation on SNS (Wang et al., 2018). Also, an advantage of seeking positive feedback in an online environment is the low risk of negative feedback compared to face-to-face interactions (e.g., Walther et al., 1996). This advantage is related to the second major contribution of our study. By linking specific self-presentational behaviors to the amount of positive feedback adolescents receive from their peers on Facebook, we are able to derive recommendations for a kind of self-presentation on Facebook that serves adolescents' development. This is intriguing because the feedback from peers in turn has an influence on adolescents' psychosocial development, namely identity construction and again the development of new and maintenance of existing social relationships (Furmann \& Buhrmester, 1993; Harter, 1999; Valkenburg et al., 2006). Therefore, adolescents could be encouraged to choose profile pictures and status updated that emphasize their social relationships and positive aspects of one's life. This kind of self-presentation increases the likelihood of positive feedback on the one hand. On the other hand it provides a starting point for offline interactions with peers. This especially might count for shy, anxious adolescent or young people with poor social skills.

Our findings therefore provide a theoretical insight into the developmental circle of young peoples' identity and social construction with self-presentational behavior and social interactions and the feedback from peers, which in turn affect the identity and social construction.

Taken together, the strategy of ingratiation appears to be most successful in eliciting positive feedback from Facebook friends among adolescents. The selfpresentational strategy of self-promotion, such as posting pictures showing the profile owner engaging in a hobby or writing a status update indicating success in something, were not related to positive feedback. This may be due to several factors. First, Facebook is a SNS that focuses on social interactions. Therefore, being perceived as socially integrated, likeable or popular may be more important than emphasizing one's competences. Other business- and employment-oriented SNSs such as LinkedIn or Xing are designed to connect professionals and might be more appropriate environments to seek social reward through self-promotion. Second, as one psychosocial goal of adolescents' development is to form and maintain meaningful relationships with others (e.g., Ellison et al., 2007), self-presentational behaviors that emphasize social connections may be evaluated as more important and gainful than self-presentational behaviors that are aimed at highlighting one's intelligence. Self-promoting behaviors such as addressing a political topic in the context of Facebook might even be perceived among adolescents as an attempt to show off. Therefore, adolescents may rather avoid this kind of selfpresentation. 


\section{Limitations and Future Directions}

Our study has some limitations. First, the crosssectional design does not allow us to draw causal inferences regarding the relationships among variables. Future studies should use longitudinal data or experimental settings. Second, we investigated a convenience sample. Participants usually have an affinity for the subject addressed by the study and therefore they might in general have a positive attitude toward Facebook. This affinity might influence their self-presentational behavior and hence the results.

Even though we employed a two-method approach using self-reported as well as observed data, there are limitations within each data source. Relating to questionnaire data, social desirability could cause a response artifact. Social desirability, a tendency to present one's most favorable image to others (Edwards, 1957), may pose a particular challenge to understanding the association between specific forms of self-presentation and positive feedback. That applies especially for the questions about the number of Facebook friends and the frequency of Likes. Adolescents with a high social-desirability bias may try to appear more popular by exaggerating the number of friends or Likes. Though a solution to this is the usage of observed data, there are other shortcomings related to this type of data collection. For instance, adolescents are increasingly concerned with their online privacy and therefore restrict the information on their Facebook profiles more often (Spies Shapiro \& Margolin, 2014). Moreover, not all information can be systematically coded due to its complexity. For this reason, we did not observe status updates via content analysis. Whereas some studies categorized status updates regarding its valence (positive vs. negative) (e.g., Forest $\&$ Wood, 2012) a categorization of qualitative aspects is hardly possible within our theoretical framework. For example, a status update has a potential maximum length of 60,000 words (Lin \& Qiu, 2013). Therefore, a status update may contain multiple statements. Moreover, some status updates contain for example short statements that are typically expressed by young people such as "YOLO" ("You only live once"). As it is not evident for the research coder whether this statement refers to an event with others or to a happy moment in one's life, a classification of this statement as one specific self-presentation strategy is hardly possible. In this perspective, it is noteworthy that the two methods in our approach led to very similar results.
Apart from these limitations, our research opens venues for future study. Whereas the current study focuses on positive self-presentational behaviors, the use of other strategies may also be successful in some cases. A recent study (Bareket-Bojmel et al., 2016) found that participants received an increased numbers of positive responses on Facebook as a result of presenting themselves in an self-enhancing manner and also as a result of presenting themselves in a negative manner such as writing status updates with a negative content (pursuing the strategy of "derogation").

Nevertheless, presenting oneself in a negative manner on Facebook was also found to be associated with the risk of undesirable responses from others. For instance, Forest and Wood (2012) found that the more negativity a status update from people with low self-esteem contained, the less users were liked by the research coders. Moreover, friends of participants with low self-esteem rewarded more positive status updates the more positive they were. The authors argue that the users' friends might try to encourage this atypical self-presentational behavior.

Interestingly, Facebook introduced five new emoticons (pictorial representations of emotional expression) in addition to the usual Like button in 2016. Users are now able to express the feelings "Love", "Haha" (laughing about something), "Wow" (being surprised), "Sad", and "Angry" with a oneclick feedback action. The emoticons "Sad" and "Angry" are especially notable, because the users now have the opportunity to express their sympathy for other users, e.g., when they write about being depressed or ill. These two emoticons may therefore be an additional way to give more sensitive feedback. It is also interesting that Facebook has not introduced a "dislike button" through which people could demonstrate that they are not in line with other users' feelings or opinions. This omission illustrates Facebook's claim to be an environment for predominantly positive and supportive interactions. It would be intriguing to examine if adolescents are interested in these new features and if people who receive this kind of more sensitive feedback benefit from it.

Finally, even (at least purportedly) positive selfpresentation on SNS can put adolescents at risk of different kinds of online attacks. For instance, Dredge, Gleeson and de la Piedad Garcia (2014) found that specific self-presentational behaviors such as the type of relationship status were related to a higher level of cyberbullying victimization for adolescents. Moreover, adolescent self-presentation is associated with the risk of sexual solicitation 
online due to the fact that youth experience a period of physical changes, including sexual development (Valkenburg \& Peter, 2011). For example, teenage girls where found to present themselves more seductively in profile pictures than boys did in teen chat rooms, for example by wearing only underwear, probably in an attempt to look especially appealing (Kapidzic \& Herring, 2011).

\section{Conclusion}

In conclusion, the present study extends prior research by examining the association between different self-presentational behaviors and positive feedback on Facebook among adolescents using questionnaire data as well as data from content analysis. Gender was found to be a significant predictor of positive feedback for youths' positive self-presentation via profile pictures regardless of the method of data collection. Overall, presenting oneself in the company of others, trying to look especially attractive as well as posting about spending time with friends were the most successful strategies in eliciting Likes on Facebook, again for both data sources. These results demonstrate that a positive self-presentation, pursuing the strategy of ingratiation and thereby emphasizing social aspects of one's life, is most beneficial in gaining social rewards among adolescents. Hence adolescents should be encouraged to use the benefits of CMC to make the best possible impression and profit from its consequences.

\section{Acknowledgments}

Anna Metzler was a scholarship holder of the "ElsaNeumann Scholarship of the State Berlin".

\section{References}

Arnett, J. J. (1999). Adolescent storm and stress, reconsidered. American Psychologist, 54, 317-326. doi:10.1037/0003066X.54.5.317

Back, M. D., Stopfer, J. M., Vazire, S., Gaddis, S., Schmukle, S. C., Egloff, B., \& Gosling, S. D. (2010). Facebook profiles reflect actual personality, not self-idealization. Psychological Science, 29, 1-3. doi:10.1177/0956797609360756

Bareket-Bojmel, L., Moran, S., \& Shahar, G. (2016). Strategic self-presentation on Facebook: Personal motives and audience response to online behavior. Computers in Human Behavior, 55, 788-795. doi:10.1016/j.chb.2015.10.033
Bargh, J. A., McKenna, K. Y. A., \& Fitzsimons, G. M. (2002). Can you see the real me? Activation and expression of the "true self" on the internet. Journal of Social Issues, 58, 33-48. doi:10.1111/1540-4560.00247

Bishop, J. A., \& Inderbitzen, H. M. (1995). Peer acceptance and friendship: An investigation of their relation to selfesteem. The Journal of Early Adolescence, 15, 476-489. doi:10.1177/0272431695015004005

Bonetti, L., Campbell, M. A., \& Gilmore, L. (2010). The relationship of loneliness and social anxiety with children's and adolescents' online communication. Cyberpsychology, Behavior, and Social Networking, 13, 279-285. doi:10.1089/cyber.2009.0215

Borca, G., Bina, M., Keller, P. S., Gilbert, L. R., \& Begotti, T. (2015). Internet use and developmental tasks: Adolescents' point of view. Computers in Human Behavior, 52, 49-58. doi:10.1016/j.chb.2015.05.029

Braithwaite, D. O., Waldron, V. R., \& Finn, J. (1999). Communication of social support in computer-mediated groups for people with disabilities. Health Communication, 11, 123-151. doi:10.1207/s15327027hc1102_2

Burke, M., Marlow, C., \& Lento, T. (2010). Social network activity and social well-being. Proceedings of the 2010 ACM Conference on Human Factors in Computing Systems (pp. 1909-1912). Atlanta, GA: Association for Computing Machinery (ACM) SIGCHI.

Burrow, A. L., \& Rainone, N. (2017). How many likes did I get?: Purpose moderates links between positive social media feedback and self-esteem. Journal of Experimental Social Psychology, 69, 232-236. doi:10.1016/j.jesp.2016.09.005

Cohen, J., Cohen, P., West, S. G., \& Aiken, L. S. (2003). Applied multiple regression/correlation analysis for the behavioral sciences (3rd ed). Hillsdale: Erlbaum. doi: $10.4324 / 9780203774441$

Cohen, S., Mermelstein, R., Kamarck, T., \& Hoberman, H. (1985). Measuring the functional components of social support. In I. G. Sarason \& B. R. Sarason (Eds.), Social support: Theory, research and applications (pp. 73-94). The Hague, The Netherlands: Martinus Nijhoff. doi:10.1007/978-94-009-5115-0

Davis, K. (2012). Friendship 2.0: Adolescents' experiences of belonging and self-disclosure online. Journal of Adolescence, 35, 1527-1536. doi:10.1016/j.adolescence.2012.02.013

Dominick, J. R. (1999). Who do you think you are? Personal home pages and self-presentation on the World Wide Web. Journalism \& Mass Communication Quarterly, 76, 646-658. doi: $10.1177 / 107769909907600403$.

Dredge, R., Gleeson, J., \& de la Piedad Garcia, X. (2014). Presentation on Facebook and risk of cyberbullying victimisation. Computers in Human Behavior, 40, 16-22. doi:10.1016/j.chb.2014.07.035

Eastin, M. S., \& LaRose, R. (2005). Alt. support: Modeling social support online. Computers in Human Behavior, 21, 977-992. doi:10.1016/j.chb.2004.02.024

Edwards A. (1957). The social desirability variable in personality assessment and research. New York: Dryden.

Ellison, N. B., Steinfield, C., \& Lampe, C. (2007). The benefits of Facebook "friends:" Social capital and college students' use of online social network sites. Journal of Computer-Mediated Communication, 12, 1143-1168. doi:10.1111/j.1083-6101.2007.00367.x

Feierabend, S., Plankenhorn, T., \& Rathgeb, T. (2015). JIM-Studie 2015. Jugend, Information, (Multi) Media [JIM-Study 2015. Youth, information, and (Multi) Media]. 
Stuttgart: Medienpädagogischer Forschungsverband Südwest. $<$ https://www.mpfs.de/fileadmin/files/Studien/JIM/2015/JIM_ Studie_2015.pdf>

Forest, A. L., \& Wood, J. V. (2012). When social networking is not working: Individuals with low self-esteem recognize but do not reap the benefits of self-disclosure on Facebook. Psychological Science, 23, 295-302. doi:10.1177/0956797611429709

Frison, E., \& Eggermont, S. (2015a). The impact of daily stress on adolescents' depressed mood: The role of social support seeking through Facebook. Computers in Human Behavior, 44,315-325. doi:10.1016/j.chb.2014.11.070

Frison, E., \& Eggermont, S. (2015b). Toward an integrated and differential approach to the relationships between loneliness, different types of Facebook use, and adolescents' depressed mood. Communication Research, 1, 1-28. doi:10.1177/0093650215617506

Furman, W., \& Buhrmester, D. (1993). Age and sex differences in perceptions of networks of personal relationships. Child Development, 63, 103-115. doi:10.2307/1130905

Gonzales, A. L., \& Hancock, J. T. (2011). Mirror, mirror on my Facebook wall: Effects of exposure to Facebook on selfesteem. Cyberpsychology, Behavior, and Social Networking, 14, 79-83. doi:10.1089/cyber.2009.0411

große Deters, F., \& Mehl, M. R. (2013). Does posting Facebook status updates increase or decrease loneliness? An online social networking experiment. Social Psychological and Personality Science, 4, 579-586. doi:10.1177/1948550612469233

Haferkamp, N., Eimler, S. C., Papadakis, A. M., \& Kruck, J. V. (2012). Men are from Mars, women are from Venus? Examining gender differences in self-presentation on social networking sites. Cyberpsychology, Behavior, and Social Networking, 15, 91-98. doi:10.1089/cyber.2011.0151

Harter, S. (1998). The development of self-representations. In N. Eisenberg (Ed.), Social, emotional, and personality development (5th ed.). Handbook of child psychology, Vol. 3 (pp. 553-617). New York: Wiley.

Harter, S. (1999). The construction of the self: A developmental perspective. New York: Guilford.

Hartup, W. W. (1996). The company we keep: Friendship and their developmental significance. Child Development, 67, 1-13. doi:10.1111/j.1467-8624.1996.tb01714.x

Helsen, M., Vollebergh, W., \& Meeus, W. (2000). Social support from parents and friends and emotional problems in adolescence. Journal of Youth and Adolescence, 29, 319-335. doi:10.1023/A:1005147708827

Hong, C., Chen, Z., \& Li, C. (2017). "Liking" and being "liked": How are personality traits and demographics associated with giving and receiving "likes" on Facebook? Computers in Human Behavior, 68, 292-299. doi:10.1016/j.chb.2016.11.048

Jones E. E. (1990). Interpersonal perception. New York: W.H. Freeman and Co.

Jones, E. E., \& Pittman, T. S. (1982). Toward a general theory of strategic self-presentation. In J. Suls (Ed.), Psychological perspectives on the self (pp. 231-261). Hillsdale, NJ: Lawrence Erlbaum.

Kapidzic, S., \& Herring, S. C. (2011). Gender, communication, and self-presentation in teen chatrooms revisited: Have patterns changed? Journal of Computer-Mediated Communication, 17, 39-59. doi:10.1111/j.1083-6101.2011.01561.x

Kim, J., \& Lee, J.-E. R. (2011). The Facebook paths to happiness: Effects of the number of Facebook friends and self-presentation on subjective well-being. CyberPsychology, Behavior, and
Social Networking, 14, 359-364. doi:10.1089/cyber.2010. 0374

Köbler, F., Riedl, C., Vetter, C., Leimeister, J. M., \& Krcmar, H. (2010). Social connectedness on Facebook - An explorative study on status message usage. Paper presented at the 16th Americas Conference on Information Systems. Lima, Peru, Paper 247. doi:10.2139/ssrn.1953431

Krämer, N. C., \& Winter, S. (2008). Impression Management 2.0. The relationship of self-esteem, extraversion, selfefficacy, and self-presentation within social networking sites. Journal of Media Psychology, 20, 106-116. doi:10.1027/18641105.20.3.106

Laghi, F., Schneider, B. H., Vitoroulis, I., Coplan, R. J., Baiocco, R., Amichai-Hamburger, Y.,...\& Flament, M. (2013). Knowing when not to use the Internet: Shyness and adolescents' on-line and off-line interactions with friends. Computers in Human Behavior, 29, 51-57. doi:10.1016/j.chb.2012.07.015

Leary, M. R., Nezlek, J. B., Downs, D., Radford-Davenport, J., Martin, J., \& McMullen, A. (1994). Self-presentation in everyday interaction: Effects of target familiarity and gender composition. Journal of Personality and Social Psychology, 67, 664-673. doi:10.1037/0022-3514.67.4.664

Leary, M. R. (1996). Self-presentation - Impression management and interpersonal behaviour. Boulder, CO: Westview.

Leary, M. R. (2007). Motivational and emotional aspects of the self. Annual Review of Psychology, 58, 317-344. doi:10.1146/annurev.psych.58.110405.085658

Lee, E., Kim, Y. J., \& Ahn, J. (2014). How do people use Facebook features to manage social capital? Computers in Human Behavior, 36, 440-445. doi:10.1016/j.chb.2014.04.007

Lenhart, A., \& Madden, M. (2007). Teens, privacy and online social networks. Retrieved 20 April, 2013 from Pew Internet and American Life Project website.< mycharhttp://www. pewinternet.org/2007/04/18/teens-privacy-and-online-socialnetworks/>.

Lin, H., \& Qiu, L. (2013). Two sites, two voices: Linguistic differences between Facebook status updates and tweets. In P. L. Rau (Ed.), Cross-cultural design. Cultural differences in everyday life (pp. 432-440). doi:10.1007/978-3-642391378_48

Livingstone, S. (2008). Taking risky opportunities in youthful content creation: Teenagers' use of social networking sites for intimacy, privacy and self-expression. New Media and Society, 10, 393-411. doi:10.1177/1461444808089415

Manago, A. M., Graham, M. B., Greenfiel, P. M., \& G., S. (2008). Self-presentation and gender on MySpace. Journal of Applied Developmental Psychology, 29, 446-458. doi:10.1016/j.appdev.2008.07.001

Manago, A. M., Taylor, T., \& Greenfield, P. M. (2012). $\mathrm{Me}$ and my 400 friends: The anatomy of college students' Facebook networks, their communication patterns, and well-being. Developmental Psychology, 48, 369-380. doi: $10.1037 / \mathrm{a} 0026338$

Mazur, E., \& Kozarian, L. (2010). Self-presentation and interaction in blogs of adolescents and young emerging adults. Journal of Adolescent Research, 25, 124-144. doi: $10.1177 / 0743558409350498$

Mehdizadeh, S. (2010). Self-presentation 2.0: Narcissism and self-esteem on Facebook. Cyberpsychology, Behavior, and Social Networking, 13, 357-364. doi:10.1089=cyber.2009. 0257

Meshi, D., Morawetz, C., \& Heekeren, H. R. (2013). Nucleus accumbens response to gains in reputation for the self relative to 
gains for others predicts social media use. Frontiers in Human Neuroscience, 7, 1-11. doi:10.3389/fnhum.2013.00439

Metzler, A., \& Scheithauer, H. (2015). Adolescent selfpresentation on Facebook and its impact on self-esteem. International Journal of Developmental Science, 9, 135-145. doi:10.3233/DEV-150163

Metzler, A., \& Scheithauer, H. (2017). The long-term benefits of positive self-presentation via profile pictures, number of friends and the initiation of relationships on Facebook for adolescents' self-esteem and the initiation of offline relationships. Frontiers in Psychology, 8, 1981. doi:10.3389/fpsyg.2017.01981

Nabi, R. L., Prestin, A., \& So, J. (2013). Facebook friends with (health) benefits? Exploring social network site use and perceptions of social support, stress, and well-being. Cyberpsychology, Behavior, and Social Networking, 16, 721727. doi:10.1089/cyber.2012.0521

Nadkarni, A., \& Hofmann, S. G. (2012). Why do people use Facebook? Personality and Individual Differences, 52, 243-249. doi:10.1016/j.paid.2011.11.007

Oberst, U., Renau, V., Chamarro, A., \& Carbonell, X. (2016). Gender stereotypes in Facebook profiles: Are women more female online? Computers in Human Behavior, 60, 559-564. doi:10.1016/j.chb.2016.02.085

Oh, H. J., Ozkaya, E., \& LaRose, R. (2014). How does online social networking enhance life satisfaction? The relationships among online supportive interaction, affect, perceived social support, sense of community, and life satisfaction. Computers in Human Behavior, 30, 69-78. doi:10.1016/j.chb.2013.07.053

Pempek, T. A., Yermolayeva, Y. A., \& Calvert, S. L. (2009). College students' social networking experiences on Facebook. Journal of Applied Developmental Psychology, it 30, 227-238. doi:10.1016/j.appdev.2008.12.010.

Prensky M. (2001). Digital natives, digital immigrants. On the Horizon, 9, 1-6. doi:10.1108/10748120110424816.

Reich, S. M., Subrahmanyam, K., \& Espinoza, G. (2012). Friending, IMing, and hanging out face-to-face: Overlap in adolescents' online and offline social networks. Developmental Psychology, 48, 356-368. doi:10.1037/a0026980

Rui, J., \& Stefanone, M. A. (2013). Strategic self-presentation online: A cross-cultural study. Computers in Human Behavior, 29, 110-118. doi:10.1016/j.chb.2012.07.022

Sas, C., Dix, A., Hart, J., \& Su, R. (2009). Dramaturgical capitalization of positive emotions: The answer for Facebook success? Proceedings of the 23rd British HCI group annual Conference on people and computers: Celebrating people and technology (pp. 120-129). Swinton, UK: British Computer Society. doi:10.1145/1671011.1671025

Schlenker, B. R., \& Leary, M. R. (1982). Audiences' reactions to self-enhancing, self-denigrating, and accurate selfpresentations. Journal of Experimental Social Psychology, 18, 89-104. doi:10.1016/0022-1031(82)90083-X

Scissors, L., Burke, M., \& Wengrovitz, S. (2016). What's in a Like?: Attitudes and behaviors around receiving Likes on Facebook. Proceedings of the 19th ACM Conference on Computer-Supported Cooperative Work \& Social Computing (pp. 1501-1510). ACM. doi:10.1145/2818048.2820066

Sherman, L. E., Payton, A. A., Hernandez, L. M., Greenfield, P. M., \& Dapretto, M. (2016). The power of the like in adolescence: Effects of peer influence on neural and behavioral responses to social media. Psychological science, 27, 10271035. doi:10.1177/0956797616645673
Smith, A. (2014). 6 new facts about Facebook. Retrieved 1 April, 2017 from Pew Research Center website.< http://www.pewresearch.org/fact-tank/2014/02/03/6-newfacts-about-facebook/.

Spies Shapiro, L. A., \& Margolin, G. (2014). Growing up wired: Social networking sites and adolescent psychological development. Clinical Child and Family Psychology Review, 17, 1-18. doi:10.1007/s10567-013-0135-1

SPSS. 2013. IBM SPSS statistics for Windows, release 22.0. Armonk, NY: IBM Corp.

Strano M. M. (2008). User descriptions and interpretations of self-presentation through Facebook profile images. CyberPsychology: Journal of Psychosocial Research on Cyberspace, 2: article 1. https://journals.muni.cz/cyberpsychology/article/view/4212.>

Subrahmanyam, K., Reich, S. M., Waechter, N., \& Espinoza, G. (2008). Online and offline social networks: Use of social networking sites by emerging adults. Journal of Applied Developmental Psychology, 29, 420-433. doi:10.1016/j.appdev.2008.07.003

Tabachnick, B., \& Fidell, L. S. (2007). Using multivariate statistics (5th ed.). Boston: Pearson Allyn \& Bacon.

Tifferet, S., \& Vilnai-Yavetz, I. (2014). Gender differences in Facebook self-presentation: An international randomized study. Computers in Human Behavior, 35, 388-399. doi:10.1016/j.chb.2014.03.016

Valkenburg, P. M., Schouten, A. P., \& Peter, J. (2005). Adolescents' identity experiments on the Internet. New Media \& Society, 7, 383-402. doi:10.1177/1461444805052282

Valkenburg, P. M., Peter, J., \& Schouten, A. P. (2006). Friend networking sites and their relationship to adolescents' wellbeing and social self-esteem. Cyberpsychology \& Behavior, 9, 584-590. doi:10.1089/cpb.2006.9.584

Valkenburg, P. M., \& Peter, J. (2007). Online communication and adolescent well-being: Testing the stimulation versus the displacement hypothesis. Journal of Computer-Mediated Communication, 12, 1169-1182. doi:10.1111/j.1083-6101.2007.00368.x

Valkenburg, P. M., \& Peter, J. (2011). Online communication among adolescents: An integrated model of its attraction, opportunities, and risks. Journal of Adolescent Health, 48, 121-127. doi:10.1016/j.jadohealth.2010.08.020

Valkenburg P. M., Sumter S. R., \& Peter J. (2011). Gender differences in online and offline self-disclosure in pre-adolescence and adolescence. British Journal of Developmental Psychology, 29, 253-269. doi:10.1348/2044-835X.002001

Van Ouytsel, J., Van Gool, E., Walrave, M., Ponnet, K., \& Peeters, E. (2016). Exploring the role of social networking sites within adolescent romantic relationships and dating experiences. Computers in Human Behavior, 55, 76-86. doi:10.1016/j.chb.2015.08.042

Van Zalk, M. H. W., Van Zalk, N., Kerr, M., \& Stattin, H. (2014). Influences between online-exclusive, conjoint, and offline-exclusive friendship networks: The moderating role of shyness. European Journal of Personality, 28, 134-146. doi:10.1002/per.1895

Walther, J. B. (1996). Computer-mediated communication: Impersonal, interpersonal, and hyperpersonal interaction. Communication Research, 23, 3-43. doi:10.1177/009365096023001001

Wang, P., Xie, X., Wang, X., Wang, X., Zhao, F., Chu, X.,... \& Lei, L. (2018). The need to belong and adolescent authentic self-presentation on SNSs: A moderated 
mediation model involving FoMO and perceived social support. Personality and Individual Differences, 128, 133-138. doi:org/10.1016/j.paid.2018.02.035

Wu, Y.-C. J., Chang, W.-H., \& Yuan, C.-H. (2015). Do Facebook profile pictures reflect user's personality? Computers in Human Behavior, 55, 880-889. doi:10.1016/j.chb.2014.11.014

Yang, C. C., \& Brown, B. B. (2016). Online self-presentation on Facebook and self development during the college transition. Journal of Youth and Adolescence, 45, 402-416. doi:10.1007/s10964-015-0385-y

Ybarra, M. L., Mitchell, K. J., Palmer, N. A., \& Reisner, S. L. (2015). Online social support as a buffer against online and offline peer and sexual victimization among U.S. LGBT and non-LGBT youth. Child Abuse \& Neglect, 39, 123-136. doi:10.1016/j.chiabu.2014.08.006

Zhao, S., Grasmuck, S., \& Martin, J. (2008). Identity construction on Facebook: Digital empowerment in anchored relationships. Computers in Human Behavior, 24, 1816-1836. doi:10.1016/j.chb.2008.02.012

Zimmer-Gembeck, M. J., \& Skinner, S. A. (2011). The development of coping across childhood and adolescence: An integrative review and critique of research. International Journal of Behavioral Development, 35, 1-17. doi:10.1177/016502541038492

\section{Bio Sketches}

Anna Metzler is a Ph.D. candidate at the Division of Developmental Science and Applied Developmental Psychology, Department of Education and Psychology at Freie Universität Berlin. Her work is supported by the "Elsa-Neumann Scholarship of the State Berlin". Her research interests include the significance of social media for adolescents and its impact on their development. She also has the license to practice as a psychotherapist for children and adolescents.

Dr. Herbert Scheithauer is Professor for Developmental and Clinical Psychology at Freie Universität Berlin and Head of the Division "Developmental Science and Applied Developmental Psychology". 